\title{
Investigations to characterize the interactions of light radiation, engine operating media and fluorescence tracers for the use of qualitative light-induced fluorescence in engine systems
}

\author{
Thorsten Schweizer $^{1}$ (D) Heiko Kubach ${ }^{1}$ (D) Thomas Koch $^{1}$
}

Received: 21 May 2021 / Accepted: 13 October 2021 / Published online: 23 October 2021

(c) The Author(s) 2021

\begin{abstract}
The light-induced fluorescence (LIF) represents an important tool for the continuous improvement and further development of combustion engine systems regarding efficiency increase. In this work, the interactions between light-emitting diode (LED) and laser diode light radiation, engine oil/fuel and three fluorescence tracers are investigated on an application-related investigation system for the design of qualitative LIF experiments. Thereby two efficient light sources for engine combustion chamber lighting are presented. For different engine oil/fuel tracer combinations, the fluorescence is examined in its intensity and its spectrum depending on the temperature, concentration and temperature history. With oil temperature variations of up to $150{ }^{\circ} \mathrm{C}$, changes in the fluorescence spectrum and fluorescence intensities that decrease by up to $80 \%$ are evident. For specific tracer oil/fuel mixtures, concentration-dependent maximum intensities and different temperature history behaviors can be revealed. The results shown support the design of spectral engine examination setups and give tracer dosage recommendations. Additionally, an engine LIF setup for in-cylinder tracking of engine operating media is presented.
\end{abstract}

Keywords Light-induced fluorescence $\cdot$ Engine combustion Chamber lighting · Concentration/temperature characterization $\cdot$ Doped engine operating media $\cdot$ Engine LIF setup

$\begin{array}{ll}\text { Abbreviations } \\ \text { LIF } & \text { Light-induced fluorescence } \\ \text { LED } & \text { Light-emitting diode } \\ \text { SPF } & \text { Short-pass filter } \\ \text { PM567A } & \text { Pyrromethene 567A } \\ \text { LSPI } & \text { Low-speed pre-ignition } \\ \text { PID } & \text { Proportional-integral-derivative } \\ \text { RPM } & \text { Revolutions per minute } \\ \text { BMEP } & \text { Brake mean effective pressure } \\ \text { SP-F } & \text { Short pass filter } \\ \text { LP-F } & \text { Longpass filter }\end{array}$

Thorsten Schweizer

thorsten.schweizer@kit.edu

Heiko Kubach

heiko.kubach@kit.edu

1 Institut für Kolbenmaschinen (IFKM), Karlsruher Institut Für Technologie (KIT), Kaiserstraße 12, 76131 Karlsruhe, Germany

\section{Introduction}

On the way to climate-neutral mobility, the increasingly complex development and improvement of engine systems are of indispensable relevance. An increase in overall system efficiency depending on the specific engine system is subjected to a variety of conflicting goals (efficiency, emissions behavior, customer requirements, etc.) and therefore requires efficient research and development tools. Light-induced fluorescence is a tried and tested tool for questions of a qualitative [1] and quantitative [2] nature. This study presents a pragmatic test system for investigating the interactions of laser and LED radiation with fluorescence tracers and liquids as well as two inexpensive high-power light sources which can be used for in-cylinder high-speed observations [3, 4]. The influencing parameters concentration, temperature and aging are examined with engine oils for modern downsizing units with three different oil/tracer combinations in their fluorescence behavior. In addition, an oil/tracer combination is assessed after the use in a combustion engine at a preignition load point. Furthermore, the concentration behavior of a fuel/tracer combination is characterized. With these findings, especially qualitative engine LIF experiments can 
be efficiently planned and designed. One application is the tracking of engine operating media movements and accumulations within the combustion chamber via minimally invasive endoscopic accessibilities, which can be used for pre-ignition mechanism synthesis [3, 4]. In the following, the physical principles of fluorescence and fluorescence quenching that are relevant to understand the results shown are briefly outlined. For a more detailed description of the complex molecular processes, reference should be made to the relevant specialist literature [5].

\subsection{Principle of light-induces fluorescence}

For certain molecules, fluorescence can result from a threestep process (see Fig. 1). In the first step the light energy of a photon (external excitation light source) is absorbed; an excited electron state $\mathrm{S} 2$ occurs (excitation). In the following excited state, which is limited in time, there are conformational changes in the molecule and a large number of possible interactions with its environment. Due to energy dissipation, the fluorescence energy level $\mathrm{S} 1$ is below the excitation energy level. This energy level can be emptied by further processes (static and dynamic quenching, förster resonance energy transfer or intersystem crossing), which reduces the quantum yield of the fluorescence radiation. In the third step, the molecule returns to its ground state S0, releasing photons (emission). The energy difference resulting from the dissipation in the second step is known as the Stokes shift [6].

\subsection{Fluorescence quenching}

A reduction in the fluorescence intensity can be triggered by a wide variety of processes and is generally called (fluorescence) quenching. The excitation is deactivated without the emission of a photon. Basically, there is dynamic and

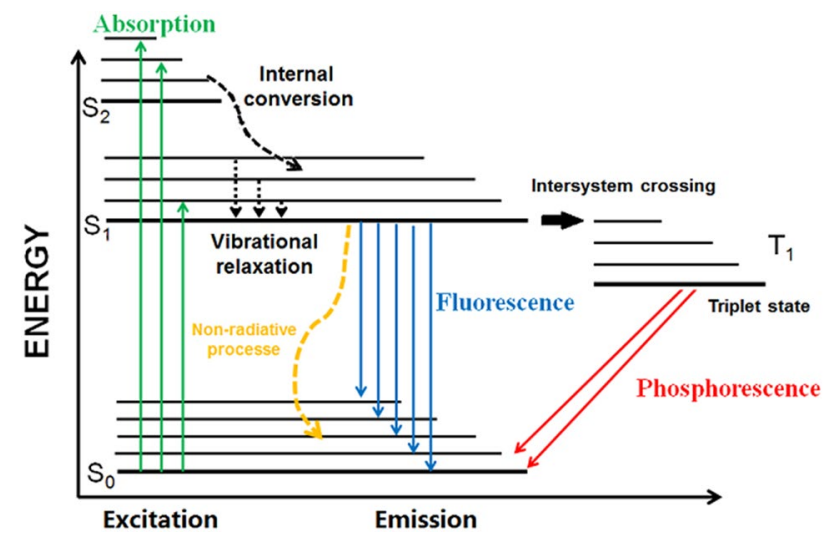

Fig. 1 Perrin Jablonski diagram of fluorescence and phosphorescence (Photophysics of fluorescent proteins 2020 [12]) static fluorescence quenching. With dynamic fluorescence quenching, also called collision fluorescence quenching, the excited state of the fluorophore is deactivated by contact with another molecule (quencher) in the solution. There are a large number of molecules that can act as collision quenchers. A very prominent representative is oxygen. Quenching effects can also appear between the fluorescent molecules themselves, which is also known as concentration fluorescence quenching. In addition to the diffusion and collisiondominated effects, the complex formation of fluorescence quenchers and fluorophores in the ground state can lead to a loss of intensity. These processes are known as static quenching. In addition, quenching effects can also occur due to non-molecular processes such as the absorption of excitation light by specific species. Long exposure to excitation light can also lead to photobleaching (chemical quenching). The ability of a molecule to fluoresce can be permanently destroyed [5].

\section{Investigation system and methodology}

Figure 2 shows an overview of the applied LIF examination system. An Acton SP2556 optical spectrometer from Princeton Instruments (focal length of $500 \mathrm{~mm}$ ) with a $200 \mu \mathrm{m}$ entrance slit in combination with the image-intensified CCD camera Princeton Instruments PI-MAX is used to record the emission spectra. The maximum resolution corresponds to $1024 \times 256$ pixels. The grating used for all experiments was $150 \mathrm{~g} / \mathrm{mm}$, which results in a detection range of approximately $192 \mathrm{~nm}$. The resolution is approx. $0.2 \mathrm{~nm}$. A fiber optic bundle with optical transmission of 190-1100 nm is used as a light guide for receiving and introducing the fluorescent light, which is held at right angles to the excitation light source in the beaker at a small distance above the liquid. The recording is made via the Spectrograph PC using WinSpec software. The trigger signal is recorded by an additional measuring unit for the fluorescence spectrum/ temperature correlation.

The excitation light is introduced on the side of the beaker just below the surface of the liquid at a short distance. For this purpose, the LED and laser systems are each fixed in a defined manner with a support structure. The light sources are energized shortly before the start of the measuring point via a laboratory power supply unit with defined parameters for a quantitative comparison of fluorescence intensity within a series of measurement. The excitation light intensity, defined by the set current, was slightly adapted for the specific tracer/fluid combination considering the intensity measuring range (Stoke-shifted fluorescent light) of the spectrometer. A quantitative comparison between the measurement series is only partially meaningful due to specific sources of measurement errors or uncertainties listed 
Fig. 2 Scheme of the fluorescence investigation system with signal paths

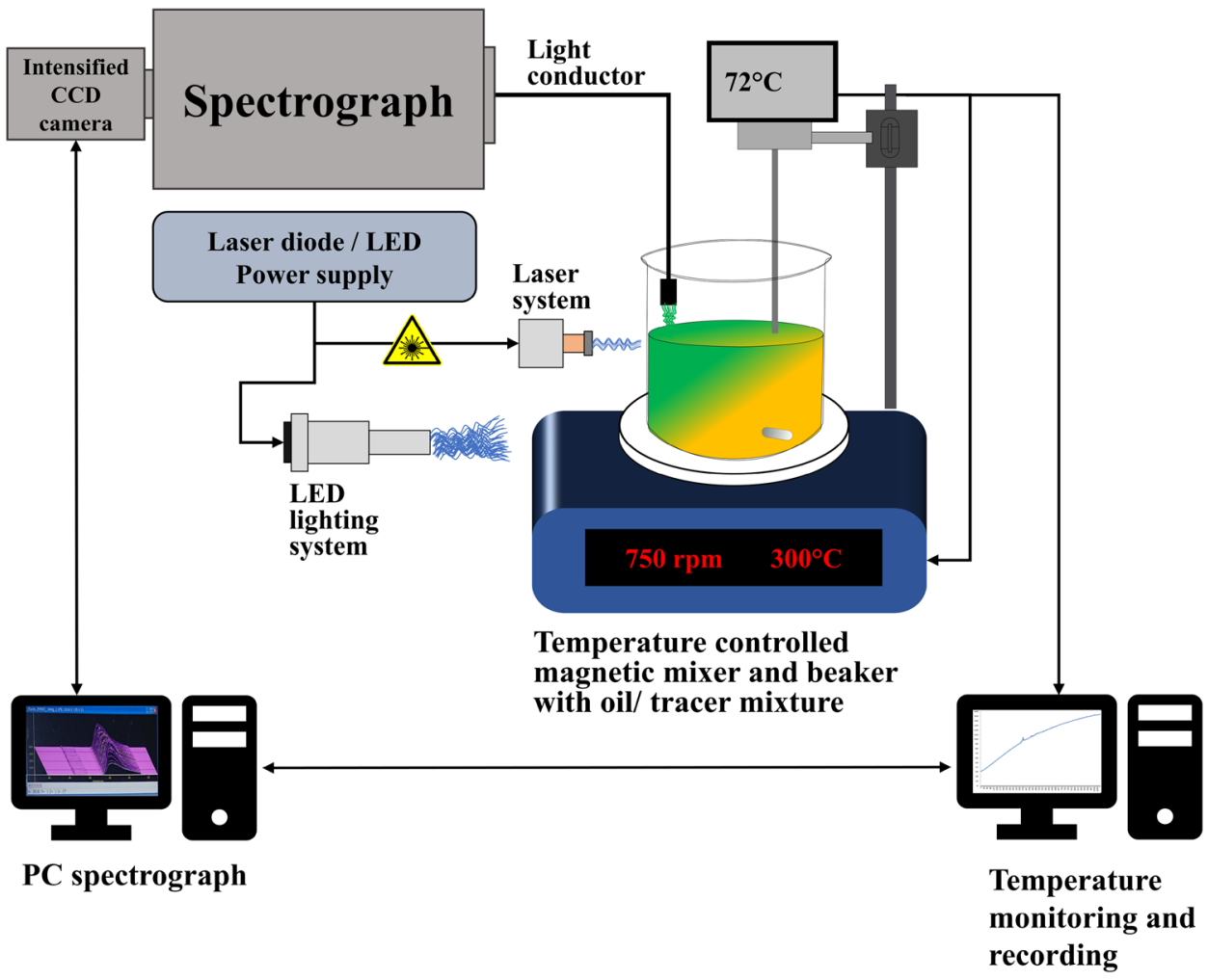

below. Specific intensities of the excitation light were not measured. Using a magnetic stirrer with integrated temperature control, the liquid/tracer mixture can be tempered and stirred in a defined manner. The movement of the liquid leads to a more homogeneous temperature distribution and avoids the cross-influence of photobleaching effects on the measurement results.

\subsection{Engine operating media, light sources and tracer}

The oil/tracer tests were carried out with the engine oils Fuchs Titan Supersyn F ECO-B 5 W-20 (Fuchs 5W20), Titan Supersyn F Eco-DT 5 W-30 (Fuchs 5W30) and Castrol Magnatec Stop-Start 5 W-20 E (Castrol). These are oils especially designed for modern Ford gasoline and diesel engines. The fuel/tracer tests were carried out with CORYTON advanced fuels "High LSPI" fuel. It has a RON value of 96.5 and is in accordance with the DIN EN 228 standard (DIN EN 228 [7]).

Light sources for engine examinations and especially for the implementation of LIF measurements should have a narrow spectral range and a high beam power. In addition, a compact design is advantageous for an efficient engine system integration. For the presented results a compact $7 \mathrm{~W}$ laser diode (NUBM44) with 3 optical lenses for beam shaping as well as a high-performance LED (Osram OSTAR ${ }^{\circledR}$ Projection Power LE B P3W 01) were used. Both light sources were typically operated with about 2.5 A direct current. The LED was cut in her spectral range with a $500 \mathrm{~nm}$ short-pass filter (SPF) and her light is guided to the beaker via a quartz glass rod through an engine access sleeve. The specific emissions spectra from the lighting systems can be seen in Fig. 3.

Three fluorescence tracers have been examined: BASF Oracet $^{\circledR}$ Yellow 084 (452.5 g/mol) (Oracet $\left.{ }^{\circledR} 084\right)$, Honeywell Lumilux ${ }^{\circledR}$ Yellow CD $345(555.8 \mathrm{~g} / \mathrm{mol})$ (Lumilux ${ }^{\circledR} \mathrm{CD}$ 345), Pyrromethene 567A (374.3 g/mol) (PM567A). These could be directly dissolved in the media and showed a clear fluorescence response when excited with the featured light sources. Pyrromethene 597-8C9 also showed good solubility but not a good quantum yield with the light sources. DCM and Rhodamine 6G could not be directly dissolved in the described engine oils. However, it should be pointed out that there are various mediators for the dissolution of these tracers, which were not considered in this study. This was derived from the idea of influencing the properties of the engine operating media as little as possible. Interesting solvents, considering the later use in engine oil, for DCM could be n-Hexane, n-Propanol and Vaseline oil [8]. The absorption of DCM dye in ethanol is descripted in [9]. The fluorescence characteristics of Rhodamine $6 \mathrm{G}$ in ethanol and butanol are investigated in [10]. Detailed different organic solvents effects of Rhodamine $6 \mathrm{G}$ can be found in [11]. 
Fig. 3 Spectra of the light sources used (left: laser diode at 0.5 A; right: LE B P3W 01 with $500 \mathrm{~nm} \mathrm{SPF}$
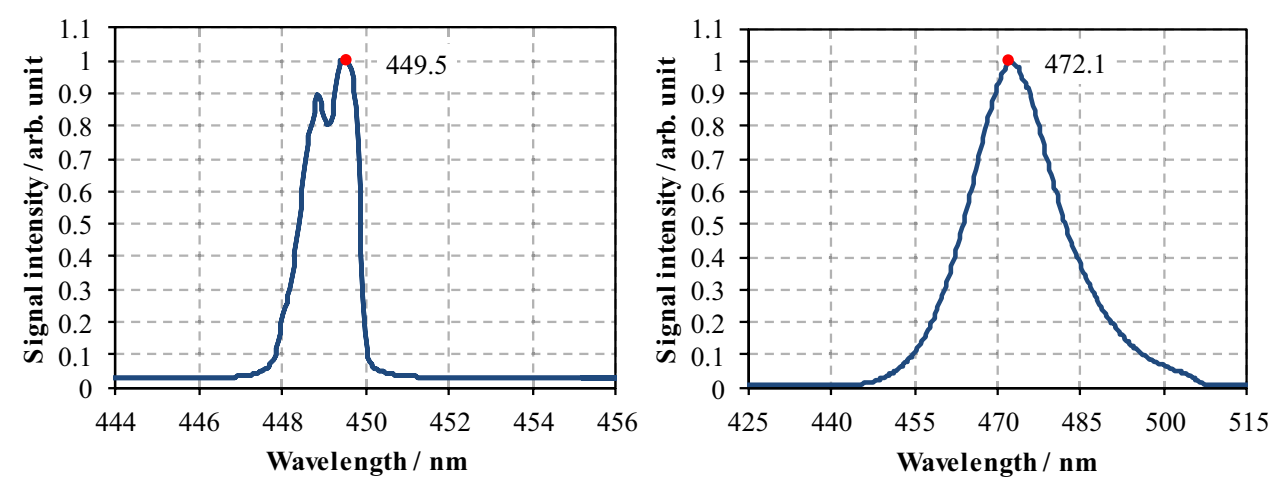

\subsection{Sample preparation}

Fresh oil and fuel were each weighed to $200 \mathrm{ml}$ and enriched with the specific tracer quantities in Duran beakers. The tracer quantities were prepared using a precision balance (Sartorius ENTRIS224-1S). For mixing, the fuel/tracer mixtures were each stirred for 5 min using a magnetic stirrer at $1500 \mathrm{rpm}$. Afterwards the oil/tracer mixtures were also dissolved in an ultrasonic bath at $60{ }^{\circ} \mathrm{C}$ for $20 \mathrm{~min}$.

\subsection{Investigation methodology}

For LIF applications, in addition to the general spectral response due to the combination of light, medium and tracer, knowledge of temperature, concentration and aging behavior is necessary for the design of the experiment.

To investigate the fluorescence characteristics (intensity, spectrum) of different tracer concentrations in oil and fuel, a defined amount of tracer is dissolved in the liquid medium $(200 \mathrm{ml})$ and then spectrally examined at $30^{\circ} \mathrm{C}$ in the beaker when excited by laser or LED light. Starting with the smallest amount of tracer, the concentration is consecutively increased in discrete steps in the same beaker. The beaker is removed for preparation after each measurement and then reinserted into the measuring device. Defined stops ensure a constant measuring position for the beaker, light introduction and fluorescence signal recording. The respective concentration series are recorded at constant temperature, spectrometer and light source parameters to ensure a quantitative relative comparison within a measurement series. The spectrometer (amplification factor, exposure time) and light source parameters (voltage, current) are coordinated with each other before each series of examinations so that the lowest expected fluorescence intensity clearly stands out from the measurement noise and the strongest fluorescence intensity does not exceed the maximum measurement limits. A quantitative comparison of different measurement series is therefore not permitted.

To examine the fluorescence characteristics (intensity, spectrum) of specific tracer concentrations at different oil temperatures, an oil/tracer combination in the beaker is continuously heated up to $150{ }^{\circ} \mathrm{C}$ on a magnetic stirrer. The heating behavior is determined by the settings of the internal control circuit of the magnetic stirrer (PID controller) and recorded via an external unit. The same setting parameters (plate temperature: $300{ }^{\circ} \mathrm{C}$, target temperature $170^{\circ} \mathrm{C}$ ) are used for all temperature tests presented. From $30^{\circ} \mathrm{C}$, three spectrographic measurements are carried out every $10^{\circ} \mathrm{C}$. A stir bar $(750 \mathrm{rpm})$ in the asymmetrically attached beaker ensures a more homogeneous temperature distribution in the oil volume. Spectrometer and light source parameters are set as described above.

To characterize the aging behavior, two specific oil/tracer mixtures were subjected to two temperature series measurements with an interval of one week each (stored in the beaker at room temperature). In the second attempt, the samples are thus subject to a temperature and time history. In addition, an oil/tracer combination was used as lubricating oil in a combustion engine and spectrally examined after the use in a twenty-minute pre-ignition operation $(1600 \mathrm{rpm}$, $200 \mathrm{Nm}$, BMEP 25.2 bar). This resulted in great mechanical stress and contamination with fuel and combustion residues of the oil/tracer combination.

Reference should be made to the following specific sources of measurement errors or uncertainties in the examination system:

The mixing process of medium and tracer can lead to concentration fluctuations. A slight rotational position change of the beaker can lead to an influence of different wall thicknesses on the light intensity and refraction. The media expansion during a temperature series results in a change in the distance between the position of the liquid surface and the light guide.

\section{Results and discussion}

For each measurement, all spectral measurement results consist of the mean value of three individual measurements taken in quick succession. The examined tracer/liquid 
combinations represent a very complex system due to the large number of different molecules and the associated great potential for interaction. The mechanisms mentioned in the discussion are only intended to represent a rough classification of the general topic and not claim to be complete.

\subsection{Self-fluorescence engine operating media}

Figure 4 shows the self-fluorescence spectrum of the engine oils Fuchs 5W20 and Castrol (left) when excited with the laser diode, normalized to the maximum intensity as well as laser light passing through the "High LSPI" fuel without generating a fluorescence answer (right). Due to the very weak fluorescence signal and the necessary amplification factors on the spectrograph, the laser excitation source can be clearly seen (at $\sim 465 \mathrm{~nm}$ ) and exceeds the signal strength of the autofluorescence despite right-angled signal recording. The spectrum of the laser diode is slightly red-shifted due to the high operating temperature. The measuring range of the spectrograph ends shortly after $625 \mathrm{~nm}$. The maxima of the emission spectra are around $520 \mathrm{~nm}$ for Fuchs 5W20 and $530 \mathrm{~nm}$ for Castrol. When the "High LSPI" fuel is irradiated, no self-fluorescence can be detected for any light source.

\subsection{BASF Oracet ${ }^{\circledast}$ yellow 084}

\subsubsection{Concentration characterization}

Figure 5 shows the emission spectra of Oracet ${ }^{\circledR} 084$ at $30{ }^{\circ} \mathrm{C}$ in Fuchs 5W20 at different tracer concentrations and the associated standardized signal intensity and peak wavelength as a function of the concentration when excited by means of a laser diode. The temperature-shifted excitation spectrum of the laser diode can be seen in the area around $465 \mathrm{~nm}$.

(In comparison to Fig. 3, the spectrum shift results in particular from the operation of the diode with larger numbers of amperes.) The spectrum is characterized by a double peak at 490 and $515 \mathrm{~nm}$ and is strongly dependent on the concentration. With increasing tracer concentration, the relative signal intensity difference between the peaks increases and the $515 \mathrm{~nm}$ peak becomes increasingly dominant. A selffluorescence excitation that increases with the concentration can be responsible for this. No relevant peak wavelength change can be observed. The concentration-dependent maximum fluorescence intensity shows a maximum in the range between 6 and $8 \mathrm{mg}$ Oracet ${ }^{\circledR} 084$. Thereafter, probably the increase in dynamic quenching effects in the form of increasing collision quenching leads to a decreasing fluorescence intensity. At $16 \mathrm{mg}$ the solubility limit seems to be reached, which is characterized by the tracer molecules beginning to settle on the bottom of the beaker.
Fig. 4 Self-fluorescence spectra of Castrol (purple, dashed) and Fuchs 5W20 (green) (left); Laser beam passing through "High LSPI" fuel (right)
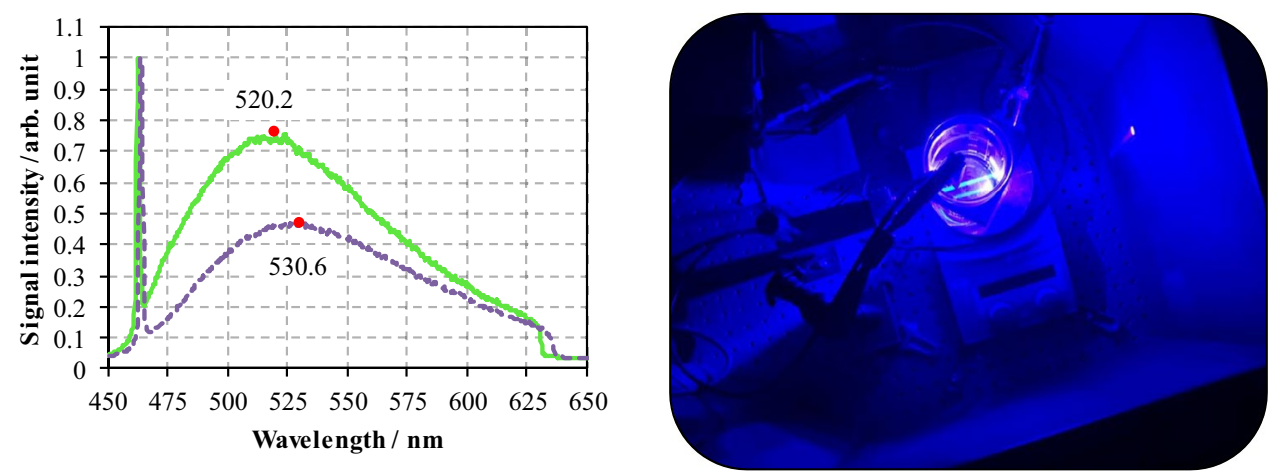

Fig. 5 Emission spectra of Oracet ${ }^{\circledR} 084$ in $200 \mathrm{ml}$ Fuchs 5 W20 $\left(30^{\circ} \mathrm{C}\right)$ with different tracer concentrations (left); Normalized signal intensity and peak wavelength as a function of the Oracet ${ }^{\circledR} 084$ concentration in $200 \mathrm{ml}$ Fuchs 5W20 (right))
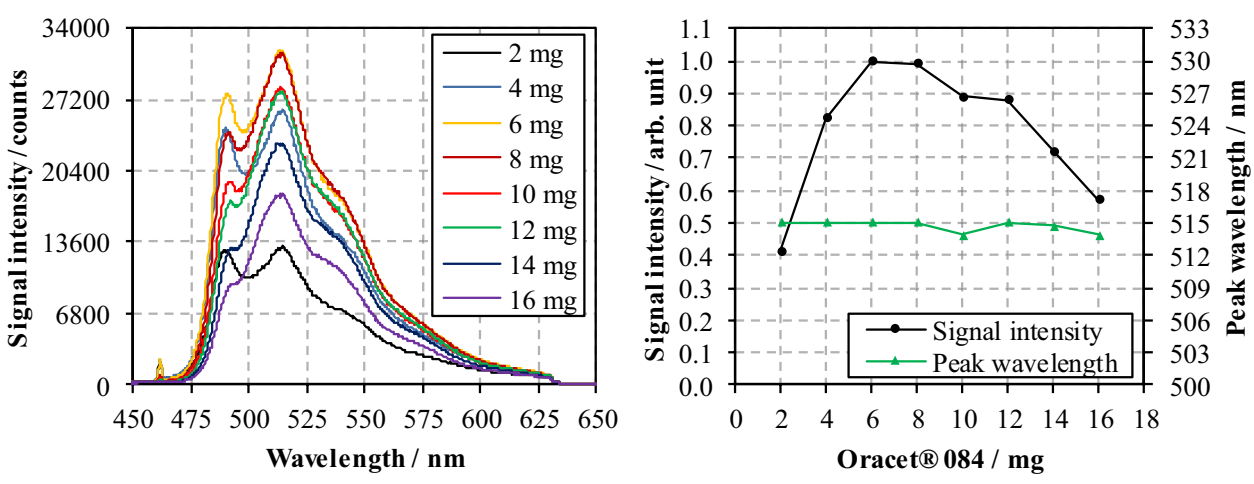
Oracet ${ }^{\circledR} 084$ also shows comparable double peak characteristics in Castrol oil (Fig. 6). The emission maximum for the investigated step size of $3 \mathrm{mg}$ is at $6 \mathrm{mg}$ Oracet $^{\circledR} 084$. A change in peak wavelength is not observed. The relative signal intensity difference between the peaks increases and, at high concentrations, leads to a strong decrease in the first peak. The underlying physical effects could be analogous to the 5W20 sample.

\subsubsection{Temperature and aging characterization}

To characterize the temperature dependence of the emission spectrum on specific tracer concentrations, this is recorded in $10{ }^{\circ} \mathrm{C}$ steps from 30 to $150{ }^{\circ} \mathrm{C}$ oil temperature. Aging is shown by running a temperature series twice per concentration at a time interval of one week.

Figure 7 shows the emission spectra of 7 mg Oracet ${ }^{\circledR} 084$ in $200 \mathrm{ml}$ Fuchs $5 \mathrm{~W} 20$ at different mixture temperatures during the second heating cycle and the associated standardized signal intensity and peak wavelength as a function of the temperature when excited by means of a laser diode. $7 \mathrm{mg}$ was in the concentration area of maximum signal intensity at $30{ }^{\circ} \mathrm{C}$ in the concentration characterization test. As a result of the increase in oil temperature, there are more and more quenching effects and thus a pronounced decrease in fluorescence intensity down to about $40 \%$ of the initial level. The increase in the temperature-dependent diffusion potential presumably leads to severe collision quenching. The first emission peak decreases over proportionally with increasing temperature and the spectrum becomes single peaked. The Stokes shift remains constant.

Figure 8 shows the normalized signal intensities and peak wavelengths as a function of temperature, concentration and number of tempering when excited by means of a laser diode in Fuchs 5W20. The two concentrations $7 \mathrm{mg}$ and $16 \mathrm{mg}$ show a marked difference in temperature behavior. When the $7 \mathrm{mg}$ mixture is heated for the first time, the fluorescence intensity increases to $70{ }^{\circ} \mathrm{C}$ and then drops to about $60 \%$ of the maximum intensity at $150{ }^{\circ} \mathrm{C}$. The spectrum at $30{ }^{\circ} \mathrm{C}$ and $150{ }^{\circ} \mathrm{C}$ shows a slightly enlarged Stokes shift. There is a comparable peak behavior to Fig. 7. In general, additional oxidation effects of the oil seem to influence the system behavior. The second heating, however, leads to a continuous decrease in intensity to about $40 \%$ of the initial level and shows a constant Stokes shift. The first heating of the $16 \mathrm{mg}$ mixture leads to a continuous decrease to below $20 \%$ of the maximum intensity with a slight increase (approx. 2\%) in the last temperature point. The Stokes shift remains at a constant level with a slight increase at $150{ }^{\circ} \mathrm{C}$. Compared to the $7 \mathrm{mg}$ mixture, it is on a slightly higher level. The second heating of the $16 \mathrm{mg}$ mixture leads to a continuous decrease in the fluorescence
Fig. 6 Emission spectra of Oracet $^{\circledR} 084$ in $200 \mathrm{ml}$ Castrol $\left(30{ }^{\circ} \mathrm{C}\right)$ with different tracer concentrations (left); Normalized signal intensity and peak wavelength as a function of the Oracet ${ }^{\circledR} 084$ concentration in $200 \mathrm{ml} \mathrm{Castrol} \mathrm{(right))}$
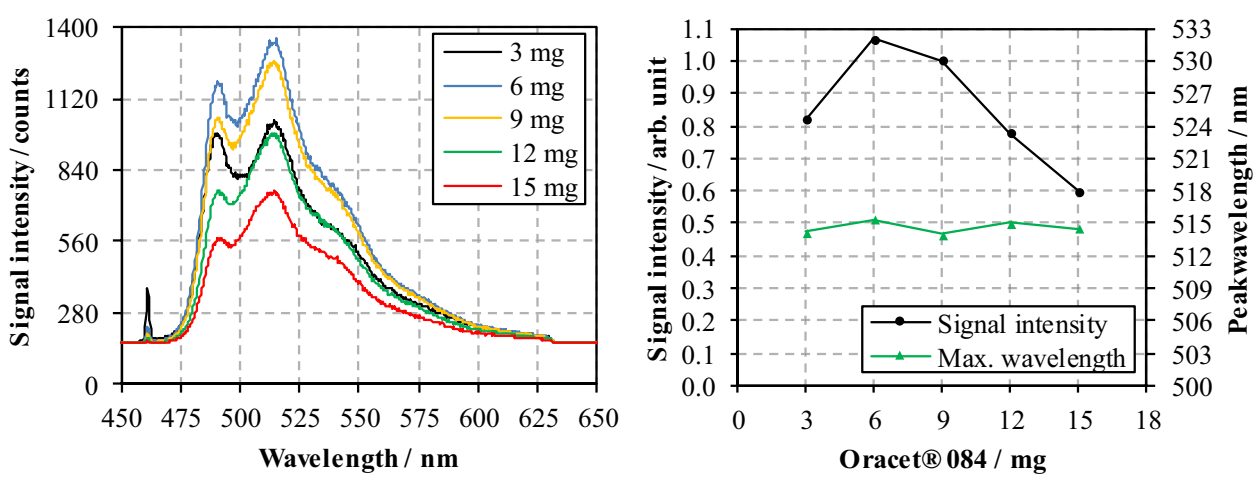

Fig. 7 Emission spectra of Oracet ${ }^{\circledR} 084(7 \mathrm{mg})$ in Fuchs $5 \mathrm{~W} 20(200 \mathrm{ml})$ at different temperatures during the second heating (left); Normalized signal intensity and peak wavelength as a function of temperature (right)
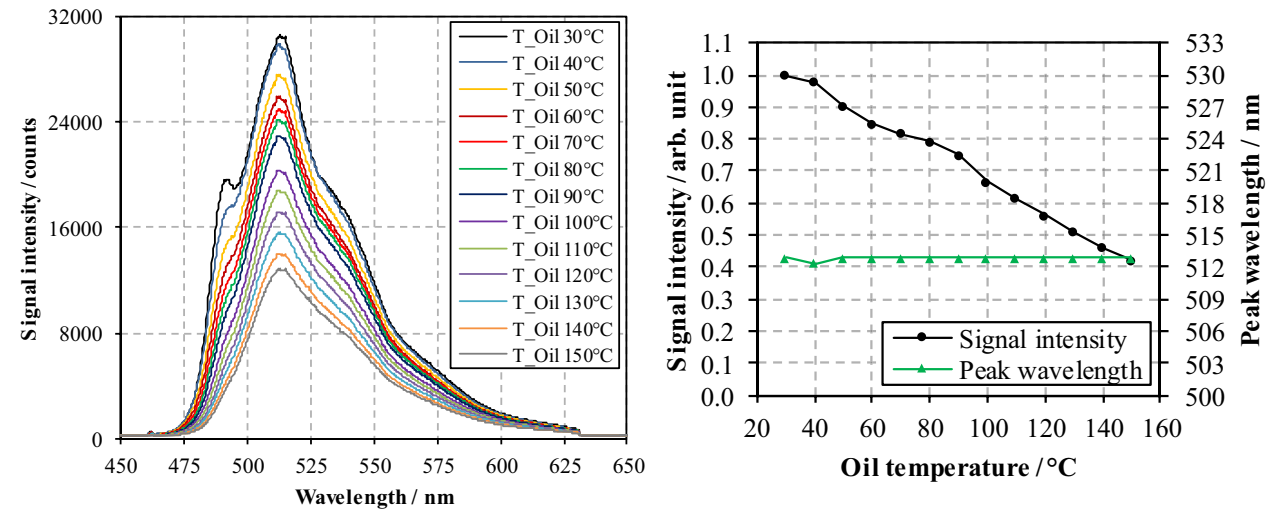
Fig. 8 Normalized signal intensity (left) and peak wavelength (right) as a function of the temperature of different Oracet ${ }^{\circledR}$ 084 concentrations and the number of temperature series in $200 \mathrm{ml}$ Fuchs 5W20
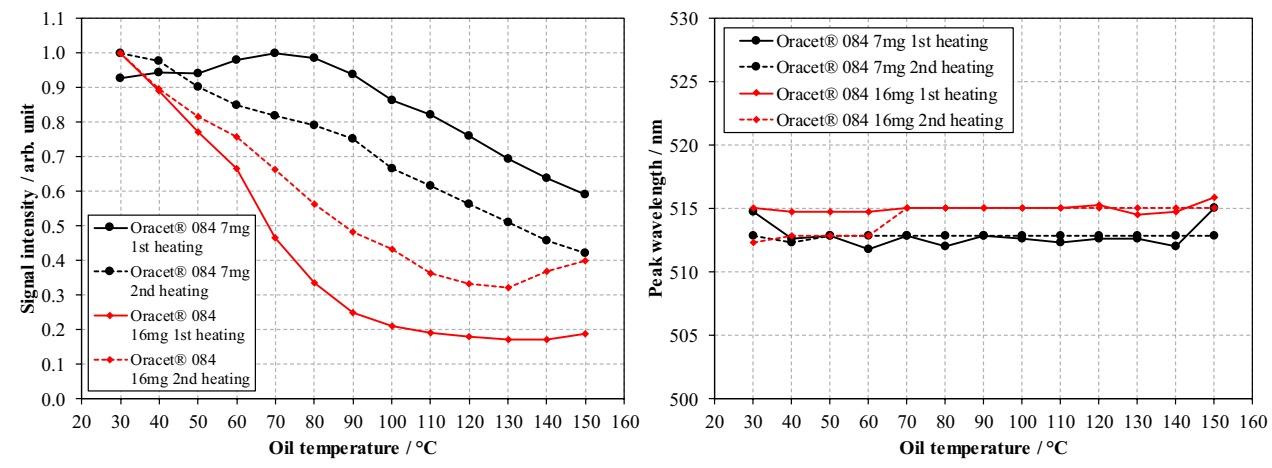

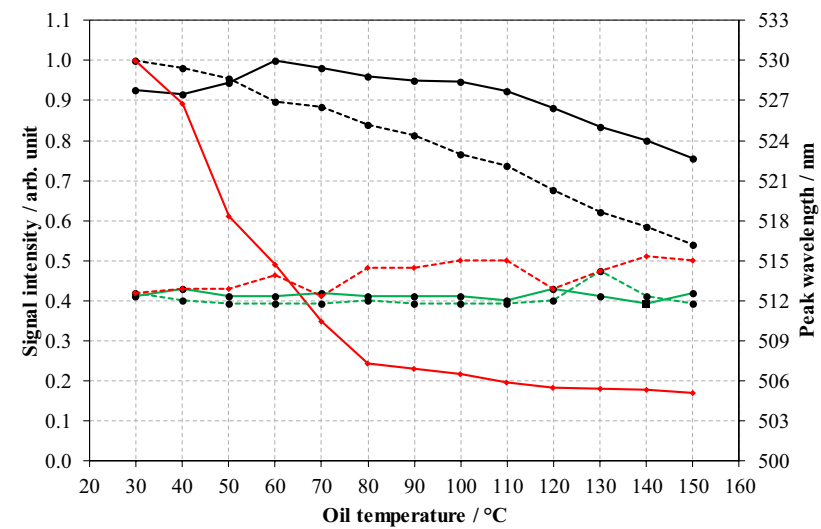

$\rightarrow-$ Signal intensity Oracet $(\mathbb{R} 084$ 8mg 1st heating $\quad--\bullet-$-Signal intensity Oracet $\mathbb{R} 084$ 8mg 2nd heating - Signal intensity Oracet $\mathbb{B} 08420 \mathrm{mg}$ 1st heating - Peak wavelength Oracet $\mathbb{B} 0848 \mathrm{mg}$ 1st heating --•--Peak wavelength Oracet $\mathbb{Q} 0848 \mathrm{mg}$ 2nd heating -----Peak wavelength Oracet $\mathbb{\complement} 08420 \mathrm{mg}$ 1st heating

Fig. 9 Normalized signal intensity and peak wavelength as a function of the temperature of different Oracet ${ }^{\circledR} 084$ concentrations and the number of tempering in $200 \mathrm{ml}$ Castrol

intensity up to $130{ }^{\circ} \mathrm{C}$ to about $32 \%$ of the initial intensity, after which a slight increase to about $40 \%$ at $150{ }^{\circ} \mathrm{C}$ can be observed. The Stokes shift in the temperature range of $30-60{ }^{\circ} \mathrm{C}$ is at the level of the $7 \mathrm{mg}$ mixture. From $70{ }^{\circ} \mathrm{C}$ it corresponds to the level when the $16 \mathrm{mg}$ mixture was heated for the first time.

Figure 9 shows the normalized signal intensities and peak wavelengths as a function of temperature, concentration and number of tempering when excited by means of a laser diode in $200 \mathrm{ml}$ of Castrol. In Castrol oil there is a very comparable picture. When heated for the first time, the $8 \mathrm{mg}$ mixture shows its maximum intensity at $60{ }^{\circ} \mathrm{C}$, after which it drops to about $75 \%$ of the maximum intensity. The second heating leads to a continuous decrease in intensity to about $54 \%$ of the initial intensity. Both series of tests show an approximately constant Stokes shift. The significantly higher dosed sample $\left(20 \mathrm{mg}\right.$ ) shows a very strong drop to $80{ }^{\circ} \mathrm{C}$ to about $24 \%$ of the initial intensity when heated for the first time. At $150{ }^{\circ} \mathrm{C}$ it still has about $17 \%$ of the intensity. In the Stokes shift, an increased level can be observed, especially from
$80{ }^{\circ} \mathrm{C}$. (A second heating with the Castrol oil was not carried out.)

Higher concentrations show a greater variance in the gradient of the signal intensity curve. An initial steeper decrease and a flatter course at higher temperatures, which generally speaks for increased interactions compared to low tracer dosages. It can be assumed that a slightly increased concentration in comparison to the $30{ }^{\circ} \mathrm{C}$ maximum intensity concentration could be advantageous for temperature and aging effects with regard to a maximum fluorescence intensity. Higher concentrations tend to shift the emission spectrum slightly to red, especially under the influence of temperature.

\subsection{Honeywell Lumilux ${ }^{\circledR}$ yellow CD 345}

\subsubsection{Concentration characterization}

Figure 10 shows the emission spectra of Honeywell Lumilux ${ }^{\circledR}$ CD 345 in Fuchs 5W20 $\left(30{ }^{\circ} \mathrm{C}\right)$ at different tracer concentrations as well as the associated standardized signal intensity and peak wavelength as a function of the concentration when excited by means of a laser diode. In the area around $462 \mathrm{~nm}$, the temperature-shifted excitation spectrum of the laser diode can be seen again. The spectrum is characterized by a double peak ( 499 and $524 \mathrm{~nm}$ ) and is strongly dependent on the concentration. A signal intensity difference between the peaks that increases relative to the concentration can only be observed weakly. The second peak becomes more dominant as the concentration increases. The concentrations 4 and $6 \mathrm{mg}$ show a slightly dominant first peak, which is why there is a peak wavelength shift here. The concentration-dependent fluorescence intensity shows a maximum in the range around $12 \mathrm{mg}$ Lumilux $^{\circledR}$ CD 345. After that, quenching effects will probably occur more intensely, analogous to Oracet ${ }^{\circledR} 084$.

Figure 11 shows the emission spectra of Lumilux ${ }^{\circledR} \mathrm{CD}$ 345 in Coryton "High LSPI" fuel $\left(17^{\circ} \mathrm{C}\right)$ at different tracer concentrations as well as the associated standardized signal intensity and peak wavelength as a function of the concentration when excited by LED light. In contrast 
Fig. 10 Emission spectra of Lumilux ${ }^{\circledR}$ CD 345 in Fuchs $5 \mathrm{~W} 20\left(30^{\circ} \mathrm{C}\right)$ with different tracer concentrations (left); Normalized signal intensity and peak wavelength as a function of the Lumilux ${ }^{\circledR}$ CD 345 concentration in Fuchs 5W20 (right)

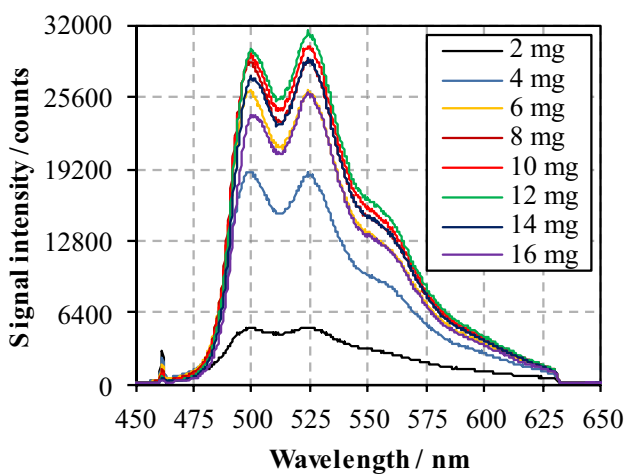

to the oil, the spectrum is characterized by a single peak at $527 \mathrm{~nm}$ and is strongly dependent on the concentration. The single peak characteristic must be due to the different molecular composition of the liquid. The concentrationdependent fluorescence intensity shows a maximum in the range between 26 and $33 \mathrm{mg}$ Lumilux ${ }^{\circledR} \mathrm{CD} 345$. After that, the quenching effects increase again. In a direct comparison to engine oil, there is a significantly better solubility and a greater concentration potential.

\subsubsection{Temperature and aging characterization}

The characterizations take place analogously to the Oracet ${ }^{\circledR}$ 084 examinations. Figure 12 shows the emission spectra of $11 \mathrm{mg}$ Lumilux ${ }^{\circledR}$ CD 345 in $200 \mathrm{ml}$ Fuchs 5W20 at different mixture temperatures during the second heating cycle and the associated standardized signal intensity and peak wavelength as a function of the temperature when excited by means of a laser diode. As a result of increasing quenching effects, there is a pronounced decrease in fluorescence intensity down to $37 \%$ of the initial level with increasing oil temperature. In all temperature series, the first emission peak
Fig. 11 Emission spectra of Lumilux ${ }^{\circledR}$ CD 345 in Coryton "High LSPI" $\left(17^{\circ} \mathrm{C}\right)$ with different tracer concentrations (left); Normalized signal intensity and peak wavelength as a function of the Lumilux ${ }^{\circledR} \mathrm{CD}$ 345 concentration in Coryton "High LSPI" (right))
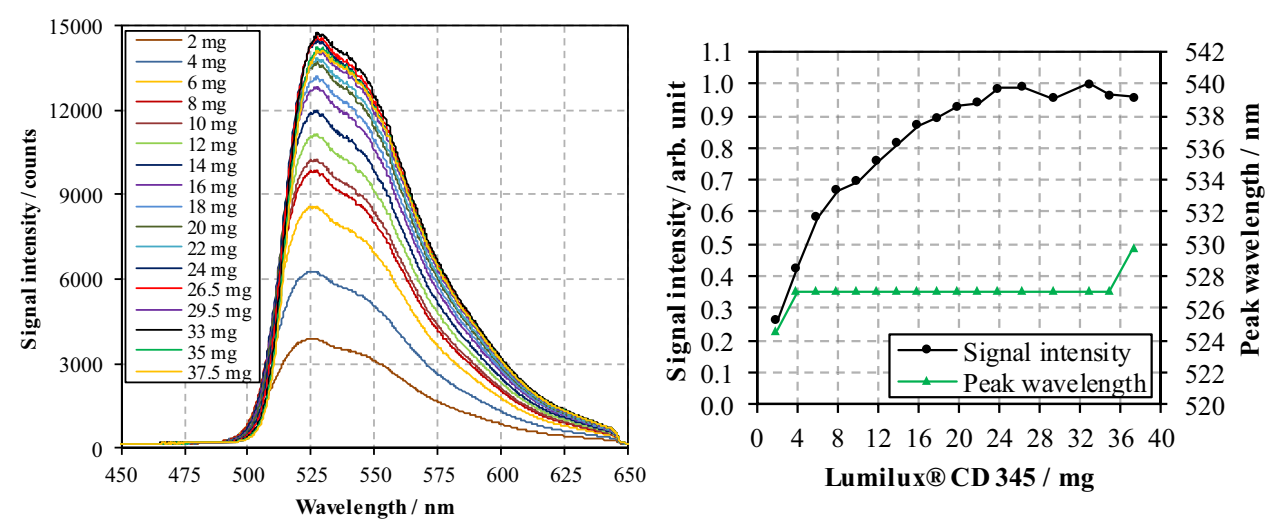

Fig. 12 Emission spectra of Lumilux ${ }^{\circledR}$ CD 345 (11 mg) in Fuchs 5W20 (200 ml) at different temperatures during the second heating (left); Normalized signal intensity and peak wavelength as a function of temperature (right)

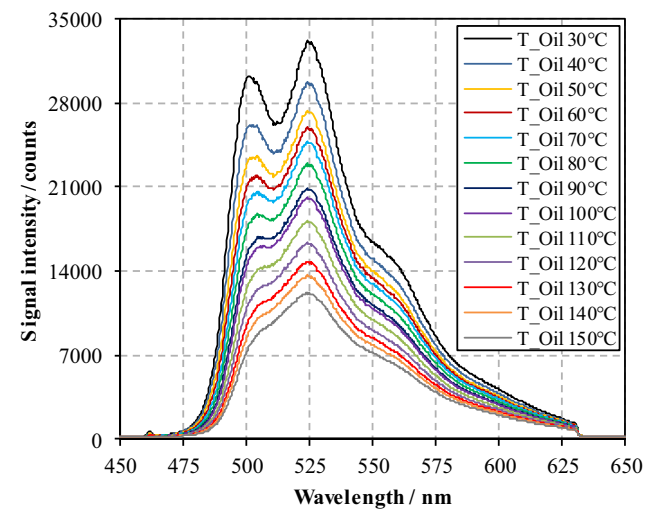


decreases with increasing temperature and the spectrum becomes single peaked. The Stokes shift remains constant.

Figure 13 shows the normalized signal intensities and peak wavelengths as a function of temperature, concentration and number of tempering when excited by means of a laser diode (Fuchs 5W20). The two concentrations $11 \mathrm{mg}$ and $16 \mathrm{mg}$ show a marked difference in temperature behavior. When the $11 \mathrm{mg}$ mixture is heated for the first time, there is a sharp drop in intensity up to $60{ }^{\circ} \mathrm{C}$ and a subsequent increase to $80{ }^{\circ} \mathrm{C}$ until it drops again to around $46 \%$. The second heating, however, leads to a continuous decrease in intensity to about $37 \%$ of the initial level. Both temperature series show a constant Stokes shift. Here, too, oil oxidation effects seem to influence the fluorescence. The first heating of the $16 \mathrm{mg}$ mixture leads to a continuous decrease in the fluorescence intensity with the exception of the $90{ }^{\circ} \mathrm{C}$ value to a final level of approx. $31 \%$. The Stokes shift remains at a constant level with slight fluctuations. The second heating leads to a continuous decrease to $46 \%$ of the maximum intensity. The Stokes shift is constant with the exception of the $30{ }^{\circ} \mathrm{C}$ value. In general, the second temperature series shows a more comparable temperature behavior of the different concentrations. Higher concentrations show again a greater variance in the gradient of the signal intensity curve. Overall, Lumilux ${ }^{\circledR}$ CD 345 and Oracet ${ }^{\circledR} 084$ show a very comparable system behavior. Again, a slightly increased concentration in comparison to the $30{ }^{\circ} \mathrm{C}$ maximum intensity concentration could be advantageous for temperature and aging effects with regard to a maximum fluorescence intensity. Aging investigations of fuel/tracer mixture have not been done due to the fuel evaporation characteristics.

\subsection{Pyrromethene 567A}

\subsubsection{Concentration characterization}

Figure 14 shows the emission spectra of PM567A in Fuchs $5 \mathrm{~W} 20\left(30^{\circ} \mathrm{C}\right)$ at different tracer concentrations and the associated standardized signal intensity and peak wavelength as a function of the concentration when excited by means of a laser diode. The spectrum has a peak at $546 \mathrm{~nm}$ and is strongly dependent on the concentration. A slight redshift
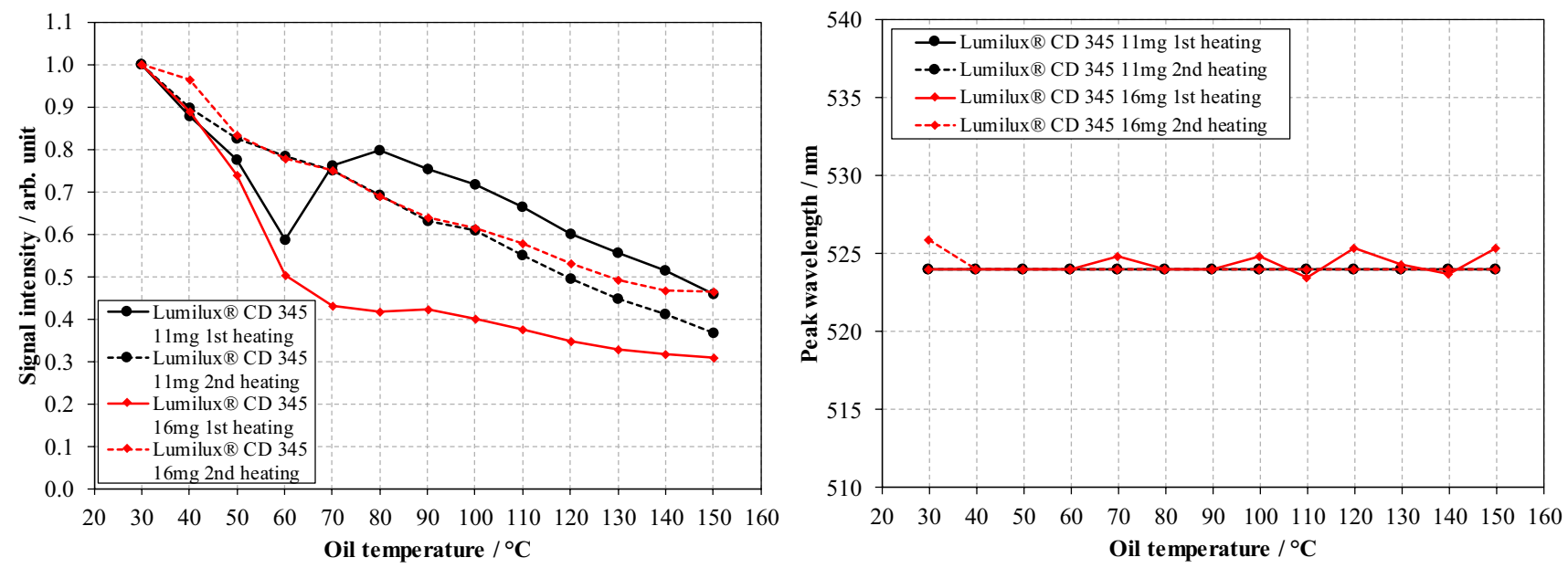

Fig. 13 Normalized signal intensity (left) and peak wavelength (right) as a function of the temperature of different Lumilux ${ }^{\circledR} \mathrm{CD} 345$ concentrations and the number of temperature series in $200 \mathrm{ml}$ Fuchs 5W20

Fig. 14 Emission spectra of PM567A in Fuchs 5W20 $\left(30{ }^{\circ} \mathrm{C}\right)$ with different tracer concentrations (left); Normalized signal intensity and peak wavelength as a function of the PM567A concentration in Fuchs Titan Super 5W20 (right)
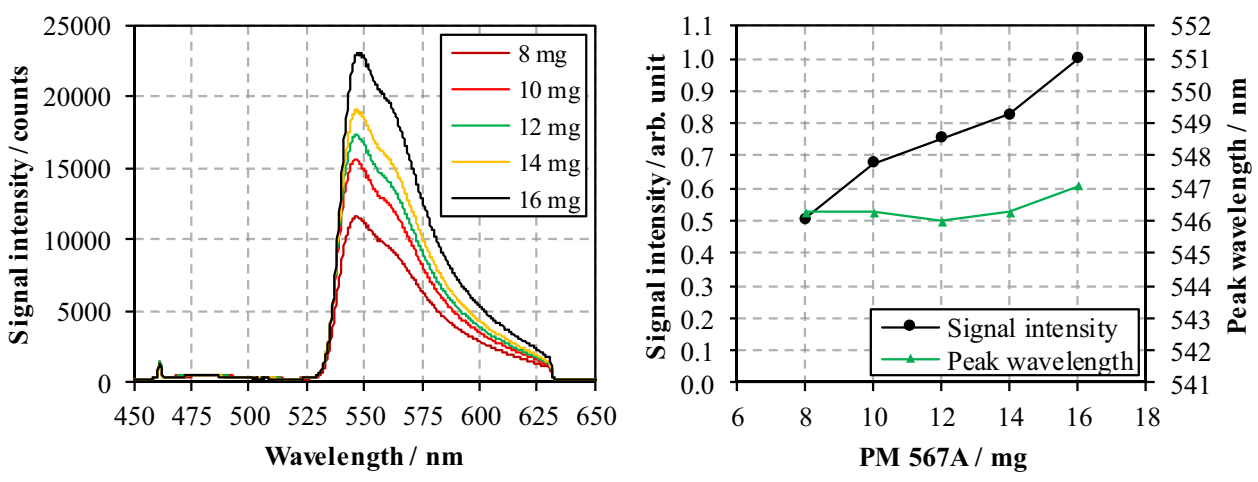
with increasing concentration can be seen. Up to $16 \mathrm{mg}$ a steady increase in intensity is visible and a slight redshift is indicated. The concentration limit is not reached.

Figure 15 shows the emission spectra of PM567A in Fuchs $5 \mathrm{~W} 30\left(30{ }^{\circ} \mathrm{C}\right)$ at different tracer concentrations and the associated standardized signal intensity and peak wavelength as a function of the concentration when excited by means of LED light. The excitation spectrum of the LED can be observed weakly in the range around $468 \mathrm{~nm}$. The spectrum shows an increasing redshift with increasing concentration. Up to $25 \mathrm{mg}$ PM567A, a flat increase in intensity is visible, which indicates that the maximum concentration potential will soon be reached.

\subsubsection{Temperature and aging characterization}

Figure 16 shows the emission spectra of $16 \mathrm{mg}$ PM567A in $200 \mathrm{ml}$ Fuchs $5 \mathrm{~W} 20$ at different mixture temperatures in the second heating cycle and the associated standardized signal intensity and peak wavelength as a function of the temperature when excited by means of a laser diode. With the exception of the $70^{\circ} \mathrm{C}$ value, a constant drop in intensity down to approx. $19 \%$ can be observed. In contrast to Oracet ${ }^{\circledR}$ 084 and Lumilux ${ }^{\circledR}$ CD 345, PM567A shows a pronounced redshift with increasing temperature.
Figure 17 shows the normalized signal intensities and peak wavelengths as a function of temperature, concentration and number of tempering when excited by means of a laser diode in Fuchs 5W20 and in Fuchs 5W30. Both temperature series with $16 \mathrm{mg}$ and excitation by means of a laser diode show a very similar behavior in terms of both the decrease in intensity and the redshift. The concentration of $25 \mathrm{mg}$ in Fuchs 5W30 also shows a comparable intensity behavior, but with a flatter intensity loss curve up to $70{ }^{\circ} \mathrm{C}$. An overall larger Stokes shift can be observed due to the higher concentration. Despite the greatest loss of intensity, PM567A shows the most similar behavior across all test series, which suggests good temperature stability. (A second heating with $25 \mathrm{mg}$ PM567A was not carried out.)

\subsection{Spectral comparison}

Figure 18 shows the spectral comparison of the tracers examined in Fuchs 5W20 when excited with a laser diode and LED. The laser spectra are recorded at an oil temperature of $120{ }^{\circ} \mathrm{C}$, whereas the LED spectra are recorded at $30{ }^{\circ} \mathrm{C}$. This can be seen in the temperature-sensitive Stokes shift of PM567A. Otherwise the characteristic features of the emission spectra are very similar. The tracer amounts have been $7 \mathrm{mg}$ for Oracet ${ }^{\circledR} 084,11 \mathrm{mg}$ for Lumilux ${ }^{\circledR} \mathrm{CD}$ 345 and $16 \mathrm{mg}$ for PM567A. Oracet ${ }^{\circledR} 084$ has the smallest
Fig. 15 Emission spectra $\left(30^{\circ} \mathrm{C}\right)$ with different tracer concentrations (left); Normalized signal intensity and peak wavelength as a function of the PM567A concentration in Fuchs 5W30 (right) of PM567A in Fuchs 5W30
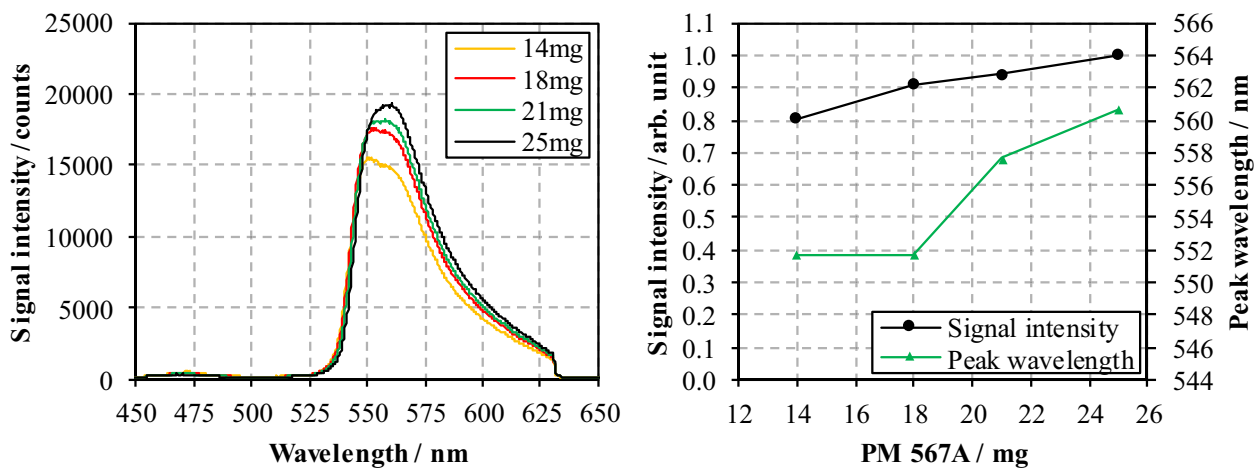

Fig. 16 Emission spectra of PM567A (16 mg) in Fuchs $5 \mathrm{~W} 20(200 \mathrm{ml})$ at different temperatures during the second heating (left); Normalized signal intensity and peak wavelength as a function of temperature (right)
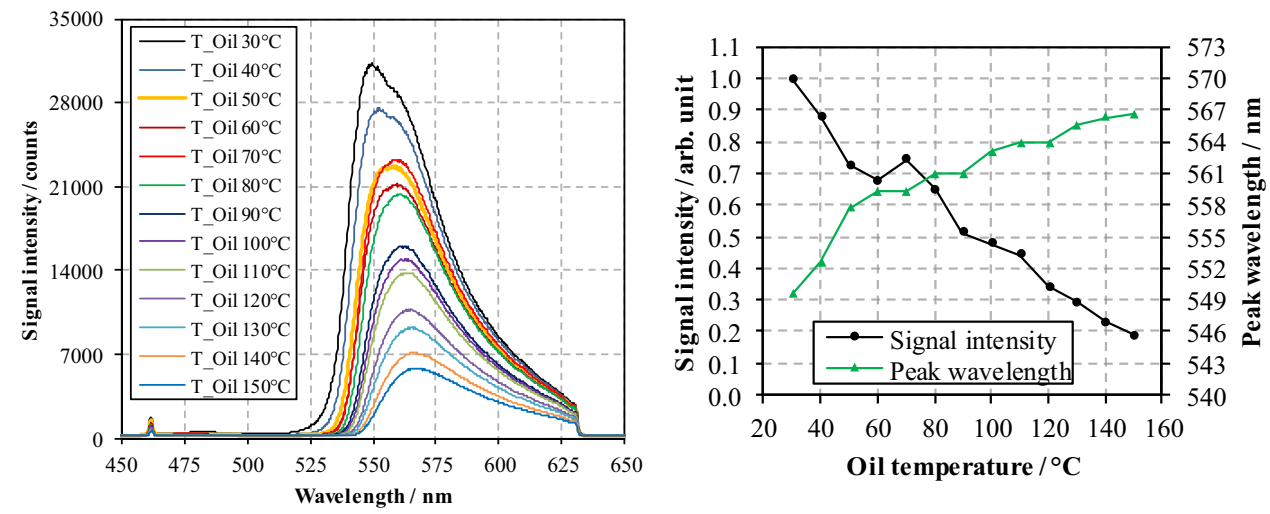

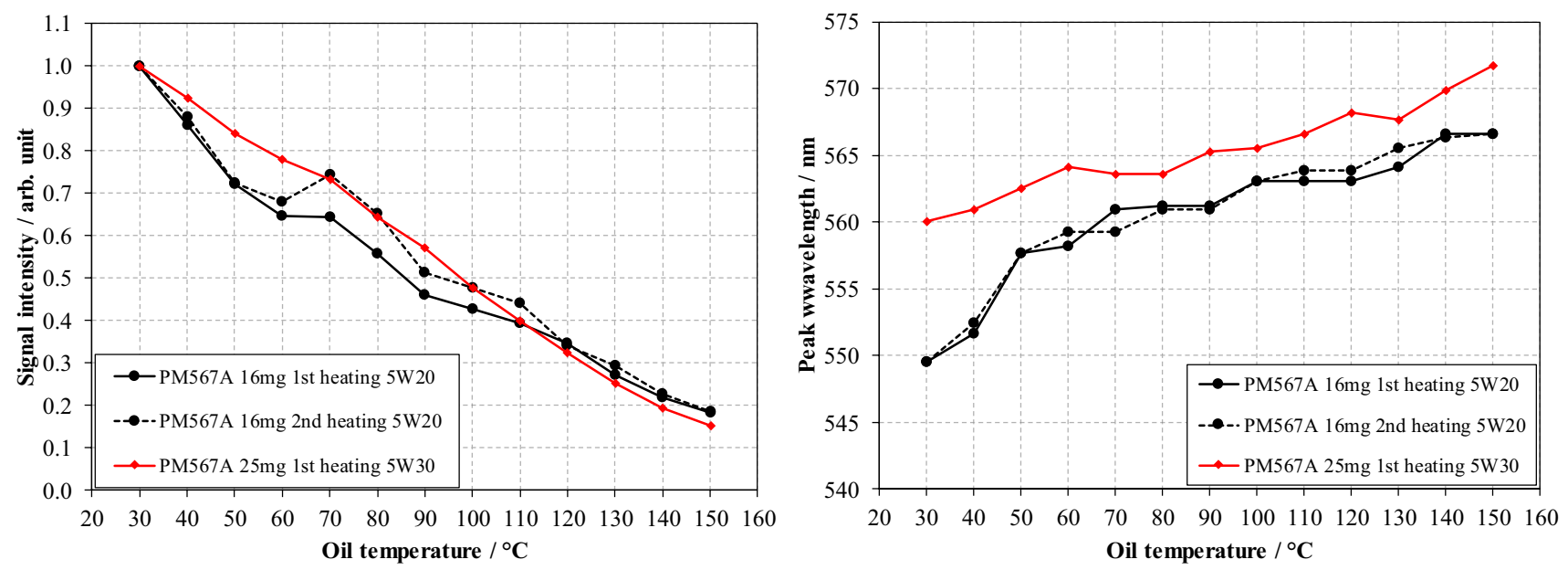

Fig. 17 Normalized signal intensity (left) and peak wavelength (right) as a function of the temperature of different PM567A concentrations and number of tempering

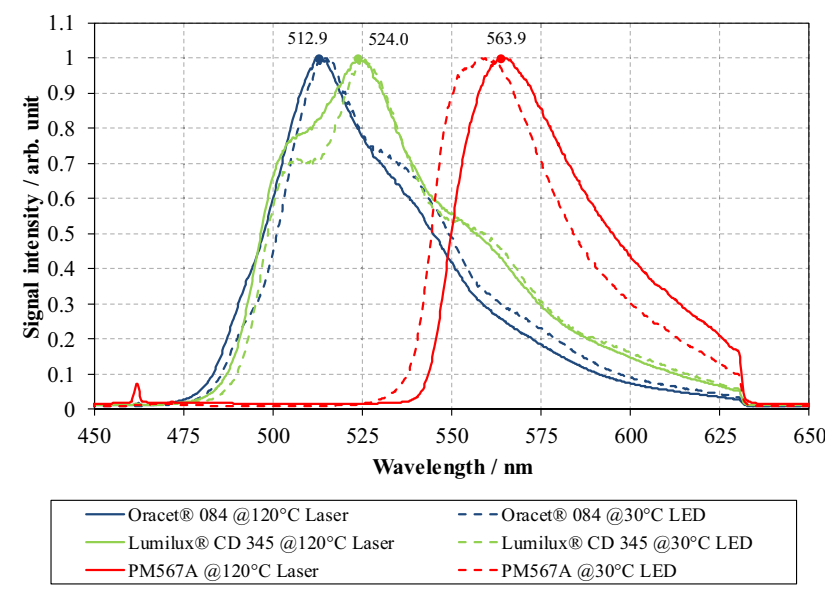

Fig. 18 Spectral overview of the examined tracers at $30{ }^{\circ} \mathrm{C}$ (LED) and $120^{\circ} \mathrm{C}$ (Laser) in $200 \mathrm{ml}$ Fuchs 5W20

Stokes shift with $58 \mathrm{~nm}$, followed by Lumilux ${ }^{\circledR} \mathrm{CD} 345$ with $62 \mathrm{~nm}$. PM567A has the largest Stokes shift with $102 \mathrm{~nm}$. The $120^{\circ} \mathrm{C}$ oil temperature comparison was chosen because of real word engine oil temperatures. In general, both lighting sources give a similar fluorescence picture.

\subsection{Use in engine operation}

In engine tests with a modern downsizing unit, a fresh engine oil batch of $3.75 \mathrm{~L}$ Fuchs $5 \mathrm{~W} 30$ was mixed with $300 \mathrm{mg}$ PM567A (^ $=16 \mathrm{mg} / 200 \mathrm{ml}$ ) and a $20 \mathrm{k}$ cycle preignition test was carried out. This $25 \mathrm{~min}$ full load engine operation puts great mechanical, thermal and chemical stress on the tracer/oil mixture. Subsequently, a drained $200 \mathrm{ml}$ oil sample was spectrally examined when excited by means of LED light. The results are shown in Fig. 19. For comparison, the spectrum of a fresh $16 \mathrm{mg} / 200 \mathrm{ml}$ PM567A/Fuchs 5W30 sample at $30{ }^{\circ} \mathrm{C}$ when excited by means of LED is shown.

Despite the harsh conditions in the engine, the tracer remains active and shows the expected behavior. In a direct comparison, the maximum of the emission spectrum is spectrally blue-shifted, which is probably due to the concentration reduction by fuel dilution. The comparable intensity of the excitation light and emission spectrum in the engine-driven oil/tracer sample in the diagram is striking, which indicates a very low general fluorescence intensity. This statement can be made on the basis of the experimental design: excitation light introduction is placed in a right angle to the fluorescence light recording. Hence the intensity difference between excitation light and fluorescence light increases drastically. This is, among other things, due to the changed optical oil properties, in particular due to combustion residues and fuel dilution, as well as the specific structure of the examination system. Figure 20 shows an application-related investigation example on an engine with minimally invasive endoscopic accessibilities. The fluorescence signal is observed by on long-pass filtered camera via an endoscope. The excitation light is introduced into the combustion chamber via two short-pass filtered LED engine lighting systems (adaption of spectral range). Due to the spectral range of the LED's the use of a $525 \mathrm{~nm}$ long-pass filter for a clear separation of excitation light and fluorescence light is necessary. Hereby a large stoke shift relates to better fluorescence light detection efficiency. Specific fuel accumulations can be detected at the liner bore top area after 
Fig. 19 Spectral comparison between an oil/tracer mixture used in an internal combustion engine and a fresh oil/tracer mixture

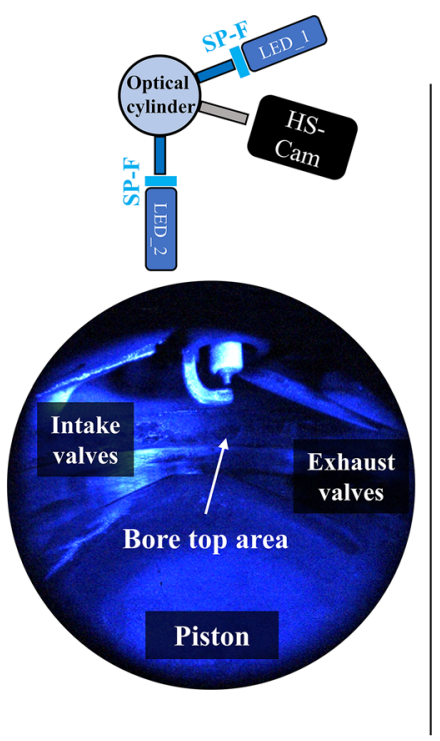

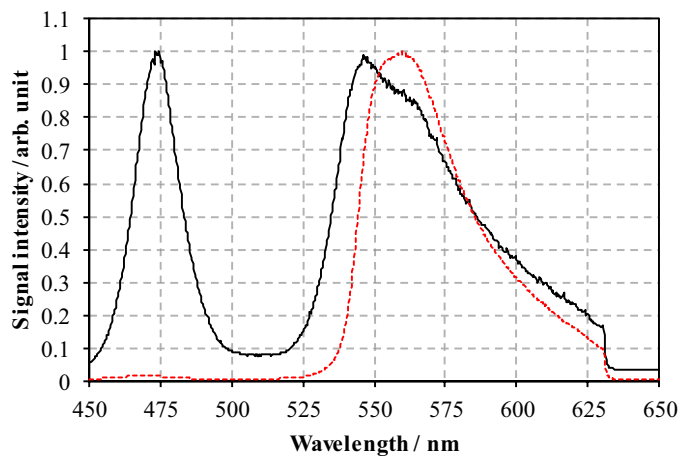

Driven engine oil + PM567A @ $30^{\circ} \mathrm{C}$ LED ---- Fresh engine oil + PM567A @ $30^{\circ} \mathrm{C}$ LED
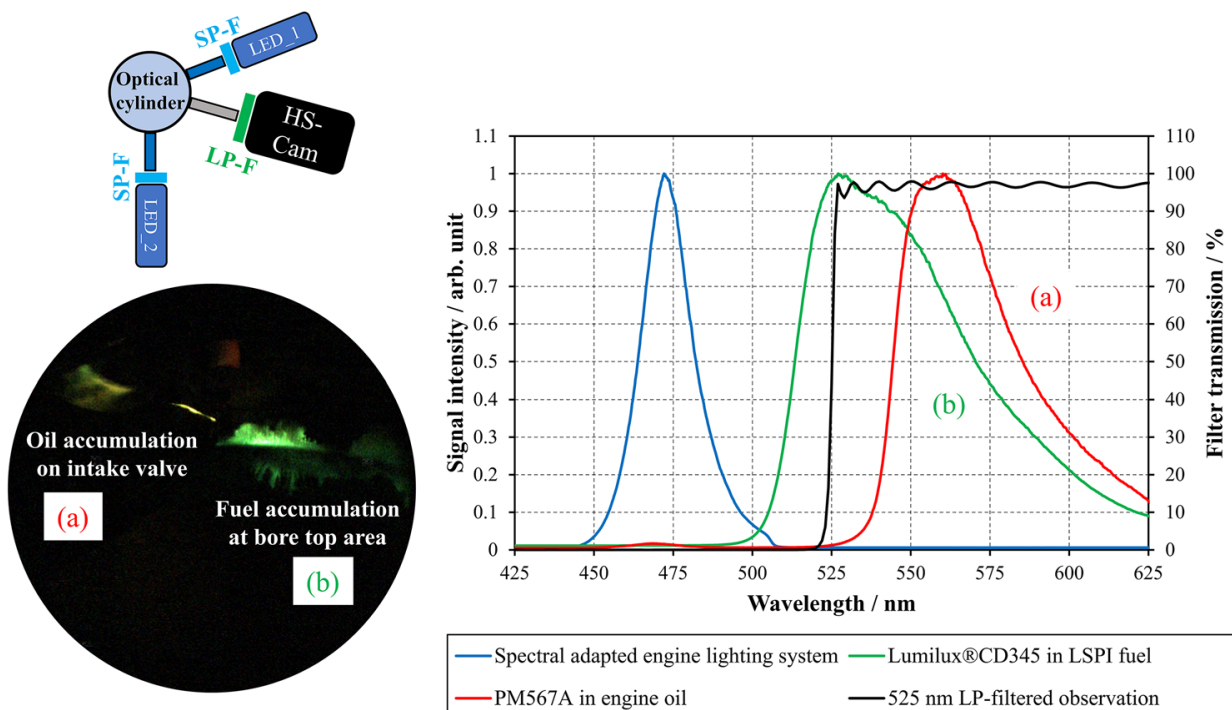

- Spectral adapted engine lighting system — Lumilux ${ }^{\circledR}$ CD345 in LSPI fuel -PM567A in engine oil — $525 \mathrm{~nm}$ LP-filtered observation

Fig. 20 Exemplary use of doped engine operating media for in-cylinder accumulation investigations with an engine LIF setup

full load engine operation, which further correlate to local deposit build-up; a sub-mechanism to pre-ignition initiation. In this special case oil accumulations on the intake valve after pre-ignition related oil injection tests can additionally be detected.

\section{Summary and conclusion}

In the investigations presented, the fluorescence behavior of Oracet ${ }^{\circledR} 084$, Lumilux ${ }^{\circledR}$ CD 345 and PM567A in engine oils when excited by a laser diode or LED was shown. In addition, Lumilux ${ }^{\circledR}$ CD 345 was also examined in fuel. The effects of concentration, temperature and aging on the fluorescence spectrum were shown using a pragmatic fluorescence investigations system. Overall, Oracet ${ }^{\circledR} 084$ and Lumilux ${ }^{\circledR}$ CD 345 showed very similar behavior, whereas
PM567A sometimes showed significant behavior differences. All tracers though can be used in engine oil.

Oracet ${ }^{\circledR} 084$ has an emission intensity maximum in the tested engine oils at $30{ }^{\circ} \mathrm{C}$ in the concentration range of 6-8 mg/200 ml. Lumilux ${ }^{\circledR}$ CD 345 shows this at around $12 \mathrm{mg} / 200 \mathrm{ml}$ for engine oil and around $24 \mathrm{mg} / 200 \mathrm{ml}$ for "High LSPI" fuel. Both tracers show a very low concentration influence on the Stokes shift. For PM567A, the concentration-dependent fluorescence maximum was not yet reached at $25 \mathrm{mg} / 200 \mathrm{ml}$ in engine oil. However, the curve trend shows that the maximum concentration potential will soon be reached. There is also a concentration-dependent redshift of the spectrum.

The temperature and aging characteristics are very constant with PM567A. At oil temperatures of $150{ }^{\circ} \mathrm{C}$, a decrease in the fluorescence intensity to below $20 \%$ of the initial intensity can be observed. There is also a clear Stokes 
shift increase with increasing temperature. Oracet ${ }^{\circledR} 084$ and Lumilux ${ }^{\circledR} \mathrm{CD} 345$ show a concentration-dependent temperature and aging behavior with an almost constant Stokes shift. Losses of intensity between 40 and $80 \%$ can be observed. With both tracers a slightly increased concentration in comparison to the $30{ }^{\circ} \mathrm{C}$ maximum intensity concentration could be advantageous for temperature and aging effects with regard to a maximum fluorescence intensity.

A large Stokes shift is advantageous for qualitative engine observations with the lighting systems used, which is why the PM567A is particularly suitable here.

Acknowledgements This work was supported by the Deutsche Forschungsgemeinschaft (DFG-German Research Foundation) Project number 237267381 Collaborative Research Center/Transregio 150 "Turbulent, chemically reactive, multi-phase flows near walls". The authors want to thank the DFG for funding this project.

Funding Open Access funding enabled and organized by Projekt DEAL.

\section{Declarations}

Conflict of interest On behalf of all authors, the corresponding author states that there is no conflict of interest.

Open Access This article is licensed under a Creative Commons Attribution 4.0 International License, which permits use, sharing, adaptation, distribution and reproduction in any medium or format, as long as you give appropriate credit to the original author(s) and the source, provide a link to the Creative Commons licence, and indicate if changes were made. The images or other third party material in this article are included in the article's Creative Commons licence, unless indicated otherwise in a credit line to the material. If material is not included in the article's Creative Commons licence and your intended use is not permitted by statutory regulation or exceeds the permitted use, you will need to obtain permission directly from the copyright holder. To view a copy of this licence, visit http://creativecommons.org/licenses/by/4.0/.

\section{References}

1. Ting, L.L.: Development of a laser fluorescence technique for measuring piston ring oil film thickness. J. Lubrication Tech. 102(2), 165-171 (1980). https://doi.org/10.1115/1.3251458
2. Stevens, R.E., Ma, H., Stone, C.R., Walmsley, H.L., Cracknell, R.: On planar laser-induced fluorescence with multi-component fuel and tracer design for quantitative determination of fuel concentration in internal combustion engines. SAGE J. (2007). https://doi. org/10.1243/09544070JAUTO162

3. Zöbinger, N., Schweizer, T., Lauer, T., Kubach, H., Koch, T.: Experimental and Numerical Analysis on Two-Phase Induced Low-Speed Pre-Ignition. Energies 14, 5063 (2021). https://doi. org/10.3390/en14165063

4. Schweizer, T., Kubach, H., Zöbinger, N., Lauer, T., Eder, M., Grabner, P., Schieß1, R., Liu, C.C.: Initial Pre-ignition. Final report for the FVV-project no. 1328 (2021)

5. Lakowicz J.R. (2006) Principles of Fluorescence Spectroscopy. Third Edition. Springer US, https://doi.org/10.1007/ 978-0-387-46312-4

6. Johnson, I.D.: Molecular probes handbook a guide to fluorescent probes and labeling technologies, 11th edn. Life Technologies, Carlsbad (2010)

7. DIN EN 228: Automotive fuels—unleaded petrol—requirements and test methods, German version EN 228:2008

8. Bondarev, S.L., Knyukshto, V.N., Stepuro, V.I., Stupak, A.P., Turban, A.A.: Fluorescence and electronic structure of the laser dye DCM in solutions and in polymethylmethacrylate. J. Appl. Spectrosc. 71(2), 194-201 (2004)

9. Nabavi, S.H., Khodabandeh, M.H., Golbabaee, M., Moshaii, A.: Absorption of DCM dye in ethanol: experimental and time dependent density functional study. Int. J. Optics Photon. 12(1), 43-56 (2018)

10. Mishra, Y.N., Yoganantham, A., Koegl, M., Zigan, L.: Investigation of five organic dyes in ethanol and butanol for two-color laser-induced fluorescence ratio thermometry. Optics 1(1), 1-17 (2020)

11. Zehentbauer, F.M., Moretto, C., Stephen, R., Thevar, T., Gilchrist, J.R., Pokrajac, D., Richard, K.L., Kiefer, J.: Fluorescence spectroscopy of rhodamine 6G: concentration and solvent effects. Spectrochim. Acta Part A Mol. Biomol. Spectrosc. 121, 147-151 (2014). https://doi.org/10.1016/j.saa.2013.10.062

12. Photophysics of fluorescent proteins, ibs Institut de Biologie Structural, France, Online https://www.ibs.fr/research/researchgroups/dynamics-and-kinetics-of-molecular-processes-group-mweik/pixel/photophysics-of-fluorescent/?lang=fr. Accessed 19 Oct 2020

Publisher's Note Springer Nature remains neutral with regard to jurisdictional claims in published maps and institutional affiliations. 